\title{
Effects of Cooperative Learning Model on Early Adolescents' Social and Affective Learning Outcomes in Physical Education
}

\author{
Simona Nicolosi, Adriano Ancona \\ Faculty of Human and Social Sciences, University of Enna "Kore", Enna, Italy \\ Email: simona.nicolosi@unikore.it
}

How to cite this paper: Nicolosi, S., \& Ancona, A. (2020). Effects of Cooperative Learning Model on Early Adolescents' Social and Affective Learning Outcomes in Physical Education. Advances in Physical Education, 10, 378-390.

https://doi.org/10.4236/ape.2020.104031

Received: September 22, 2020

Accepted: November 3, 2020

Published: November 6, 2020

Copyright (c) 2020 by author(s) and Scientific Research Publishing Inc. This work is licensed under the Creative Commons Attribution International License (CC BY 4.0).

http://creativecommons.org/licenses/by/4.0/

\section{Open Access}

\begin{abstract}
The study examined the effect of two different teaching strategies on social skills, physical self-esteem, and physical self-concept, in a sample of Italian Early Adolescents. One hundred and twenty-eight students $(\mathrm{M}=62 ; \mathrm{F}=66)$, from 11 to 14 years old $(M=12.01, S D=0.50)$, attending their Physical Education classes, were involved. Participants were divided into an intervention group $(n=60)$ and a control group $(n=68)$. The intervention group was engaged in PE lessons based on the Cooperative Learning model with a focus on positive interdependence between group mates and interpersonal skills in completing shared tasks, while the control group participated in PE lessons conducted through competitive games, individual drills and repetition of exercises as a means of perfecting skills and procedures. In both groups, social skills, physical self-concept, and physical self-efficacy were measured before and after the intervention. The intervention had a significant positive impact on perceived sports competence in boys, but no effect in girls. Related to the duration of the study, other positive effects in boys were higher levels of physical self-efficacy and lower levels of environmental pressure and tendency to psycho-somatization, while in girls lower levels in external locus of control were observed. Implications for physical education programs and physical self-research were discussed.
\end{abstract}

\section{Keywords}

Physical Self-Concept, Perceived Sports Competence, External Locus of Control, Psycho-Somatization, Social Pressure

\section{Introduction}

Physical Education (PE) literature has highlighted that changes in existing cur- 
riculum contents and teaching methods are needed due to emerging obesity and other health problems among children and adolescents (Thorburn, Jess, \& Atencio, 2011). As Tinning noted (2012), the most widely used method in teaching PE curriculum consists of teacher demonstration and explanation of what needs to be learned, with an emphasis on instructions, individual drills, and repetition of exercises as a means of perfecting skills and procedures (Dyson \& Casey, 2012). Kirk (2005) observed that in traditional PE lessons pupils receive fragmented and poorly contextualized learning experiences. This results in a small number of opportunities for promoting a deeper engagement in physical activity that make the educational contents meaningful. However, in the last three decades a growing number of studies have shown the efficacy of Cooperative Learning model that enables students to reach important learning outcomes at various grade levels (Grineski, 1993; Dyson \& Strachan, 2004; Dyson \& Casey, 2012).

Cooperative Learning (CL) is a student-centered approach in which members of a small group collaborate in order to achieve shared goals, solve a problem, make decisions, or complete a task. The elements that make this learning process cooperative were defined by Johnson, Johnson, and Holubec Johnson (1994) as perceived positive interdependence between members of a group, promotive interaction, individual accountability, personal responsibility to reach the group's goals, and use of interpersonal skills. There are numerous interpersonal and small-group skills that influence the success of cooperative efforts. This is the aspect that makes cooperative learning much more complex than competitive or individualistic methods. In order to work effectively together, students must possess a variety of social skills, such as assertiveness, democratic decision making, and encouraging participation of others. To coordinate their efforts, students must know and trust each other, communicate clearly and precisely, accept and support each other, and resolve conflicts constructively (Johnson et al., 1994). In a positive cooperative and relational context, students have the opportunity to work together, to learn from each other, and, ultimately, to extend their repertoire of social skills. If, as often happens, students do not possess high social skills, these can be taught by the teacher as a lesson content.

An essential part of the cooperative learning model is that social skills are taught like any other educational content, because of the centrality of social skills in learning processes and in personal development. The person with good social skills is able to activate a series of behaviors such as to analyze themselves and their environment, correctly discriminate their own emotional states and those of others, adequately communicate his instances by expressing feelings and opinions, both positive and negative. The identification and pursuit of one's own goals, influencing the environment to one's own advantage, without damaging others, nor provoking in others conflicts or feelings of revenge or rejection, is called assertiveness. On the contrary, maladjustment, or inability to relate to the environment in a positive way, is related to the lack of one or more social skills, which can lead to a situation of social incompetence where forms of passivity, 
states of high anxiety, depressive states, uncontrolled aggressive behavior, external locus of control, and hostile impulsiveness generate reactions of rejection in the interlocutors. Following a social cognitivist approach, an individual who possesses assertive abilities is not crushed by the pressures that the environment produces on him, but, on the other hand, is not even endowed with absolute control over the events he lives, his emotions or his motivational level. This explanatory dynamic assigns to each individual the possibility of actively influencing the events in their environment (human agency). This strong interindividual variability implies a mediation between the environmental, cognitive and behavioral components (Di Nuovo \& Magnano, 2013).

Results of the meta-analysis of studies by Babic et al. (Babic, Morgan, Plotnikoff, Lonsdale, White, \& Lubans, 2014) showed that physical self-concept and its sub-domains are associated with physical activity in children and adolescents. Physical self-concept has been defined as a hierarchical and multifaceted set of perceptions and descriptions concerning the whole physical experience about oneself. In Shavelson and Marsh's model (Marsh \& Shavelson, 1985), physical self-concept has a hierarchical organization of factors in which self-esteem is at the apex level of the hierarchy and physical self is at the domain level-as in the Physical Self Worth model by Fox and Corbin (1989) - and it includes the subdomains appearance, health, body fat, and performance. In turn, performance brings together six factors at a lower level: strength, endurance, flexibility, coordination, physical activity, and sports competence (Meleddu, Scalas, \& Guicciardi, 2002). Marsh and Peart (1988) showed that physical self-concept is related to physical competence, physical activity participation, and other indicators of fitness. Potential barriers to participation in physical activities in children are constituted by low actual and perceived physical abilities, low physical fitness levels, and obesity (Khodaverdi, Bahram, \& Robinson, 2015). Other studies showed that during early adolescence, there is a decline in physical self-concept, especially in girls. Esnaola Etxaniz's study (2008) showed that 12 - 14 years old girls have lower scores than boys in Self-esteem and Physical Self Concept sub-domains, such as physical appearance, physical condition, physical ability, and strength. Several intervention studies that analyzed the relationship between physical self and physical activities or sports in adolescence have shown contradictory results. In these studies, the interventions differed in time, total duration, and activities. In a review of exercise intervention studies 37 randomized and 42 non-randomized controlled trials were included, investigating the effects of sport programs on self-perception and self-esteem. Results indicated that $78 \%$ of the studies achieved significant effects on physical self-perception and self-esteem, despite less than half being based on sampling designs with control groups (Fox, 2000). In two studies, Daley $(2002,2007)$ showed that the participants involved in extracurricular physical activities had significantly higher scores in perceived physical appearance and in self-esteem, although there were differences between gender, and boys had higher scores in self-esteem, physical competences, and physical appearance than girls. Crocker et al. (2003) showed that changes in 
body attractiveness were associated with levels of physical activity and diet in adolescent girls. The study of Lindwall and Lindgren (2005) examined the effects of an exercise program on physical self and physical social anxiety in a sample of non-physically active adolescent girls. Participants chose one of the many sports promoted by the program and followed the 6-month exercise intervention. The intervention had positive changes in all of the physical self-dimensions and a decrease in anxiety levels. Few longitudinal well-designed intervention studies have investigated the effects of physical activities and sports programs on self-esteem, physical self-perception, and sport competences in adolescents (Lindwall \& Lindgren, 2005). Schneider, Dunton, and Cooper (2008) observed the impact of a 9-month school-based intervention for sedentary adolescent females. However, authors found no changes in physical self-concept.

In the 90's, Grineski (1996) reported outcomes of the CL model on cognitive and motor learning goals within the field of physical education, showing how physical education goals and more positive social interactions can be achieved through cooperative goal structures in children with and without emotional and behavioral disorders. More recently, Dyson, Linehan, and Hastie (2010) showed that cognitive and social tasks consistently contributed to learning outcomes in PE contexts.

Several studies showed that CL also yields positive effects in the affective domain, promoting behaviors such as trust, acceptance, helping, working together for goal achievement. CL can enhance self-esteem as a result of an increased individual accountability in reaching common goals. Cooperative Learning in Physical Education develops interpersonal and social skills in a more inclusive and supportive learning context (Dyson \& Casey, 2012; Barrett, 2005; Casey et al., 2009; Goudas \& Magotsiou, 2009, Lafont et al., 2007). In a study by Dyson and Strachan (2004), PE high school teachers concluded that the CL model developed motor skills and game strategies, but also improved the students' active participation, their communication skills, respect for others, and accountability. Furthermore, Navarro-Paton et al. (Navarro-Paton, Rego Ferreira, \& García García, 2018) found that CL model affected significantly the physical self-concept and its subdimensions in a sample of primary school' children.

Italian policies of the Ministry of Education for primary school (5 - 10 years) and middle school (11 - 14 years) (Ministerial Decree 31 July 2007; Ministerial Decree 16 November 2012) oriented the curriculum objectives for physical education towards a greater consciousness in physical self-knowledge and an enhanced use of movement as an educational tool for a more complete development of psychological, physical, and social well-being. Furthermore, PE should embrace the larger principle of supporting lifelong engagement in Physical Activity and healthy lifestyles in children and adolescents. In Italy, above all over the last fifteen years, CL has become more widespread at school through both community of practice and a research-based approach (Ellerani, 2017; Ellerani, 2014). To our knowledge, Italian research has assessed learning, and the affective and social outcomes of the CL model, in various school subjects, while there are 
still few studies that have directly measured the effects in PE (Nicolosi et al., 2010; Raiola, 2014; Raiola \& Tafuri, 2015). These studies assessed the effects of more complex approaches or teaching methods in PE, such as the Ecological-Dynamic Approach and Interdisciplinary PE models. However, in these studies, CL was not the only teaching method and its effects were not directly assessed, so the findings could not clearly be attributed to the efficacy of this model. The intervention study by Nicolosi et al. (2010) investigated the impact of an interdisciplinary PE program, with lessons carried out with cooperative small groups, in a sample of early adolescents. The intervention group' girls had significant time $\mathrm{x}$ group interactions in external locus of control, social anxiety, and perceived social pressure, with posttest scores significantly lower than pretest scores. Whereas the effects observed in boys were due to time changes and not the intervention. Nevertheless, this study is useful to show how an interdisciplinary intervention program can lead to an enhancement of perceived social abilities in girls in an Italian PE context.

Thus, the purpose of the present study was to assess the effects of two different teaching strategies on social skills, physical self-esteem, and physical self-efficacy, in a sample of Italian Early Adolescents enrolled in middle school PE class. The hypothesis is that PE lessons based on positive interdependence between group mates in completing shared tasks will improve the participants' social skills and physical self-concept more than traditional methodology conducted through individual drills and repetition of exercises, as a means of perfecting skills and procedures.

\section{Method}

\subsection{Participants}

A quasi-experimental study with a pretest-posttest non-equivalent group design was used to involve participants in this study. Class groups were maintained to further permit a contextual and ecological analysis of game-centered approach interventions, as recommended by Harvey and Jarrett (2014).

Study participants were 128 early adolescents (62 males and 66 females), aged between 11 and 14 years $(M=12.01, S D=0.50)$, attending the $7^{\text {th }}$ and $8^{\text {th }}$ grade in three public middle schools. The middle schools are located in three towns in the South of Italy, in the same school district, and in a similar socio-economic and cultural context.

Participants were divided into an intervention group $(\mathrm{n}=60 ; 31$ males and 29 females) and a control group $(n=68)$. The intervention group was engaged in PE lessons, based on the Cooperative Learning model with a focus on positive interdependence between groupmates and interpersonal skills in completing shared tasks. The remaining 68 adolescents ( 31 males and 37 females) composed the control group, that participated in their regular PE lessons conducted through individual drills and repetition of exercises as a means of perfecting skills and procedures. 


\subsection{Procedures}

A 6-month pretest-posttest design was used to test the targeted variables. In both the intervention group and in the control group, the assessments were carried out before (pretest) and after the intervention (posttest). Data were collected at school in two collective administration sessions for each classroom. The study was authorized by the headmaster of each school and written consent was signed by parents after a meeting explaining the study's aims and procedures. Additional meetings were held with the intervention group participants' parents to explain the goals of the educational activities.

Measures were assessed by an author of this paper, who explained how to fill out the questionnaires and guaranteed confidentiality and anonymity of responses. The students were offered the opportunity to refuse to participate in the research project, at any time and for any reason. In every administration session, the opportunity to clarify any doubts was provided. At the end of each administration the correct compilation of each questionnaire was verified. A single PE teacher followed both the groups in all three schools.

The intervention was carried out in the PE classes, during the regular Italian PE school curriculum (two hours per week). Intervention group was involved in two-hour sessions per week for 6 months. The PE lessons were based on Cooperative Learning goal structures designed by the PE teacher and the authors of this report, using the following key elements: instruction time, management time, team roles, and self-evaluation criteria. Working in small groups, the students were given written detailed team sheets or task cards. Small groups were involved in cooperative games, with a focus on positive interdependence between groupmates and specific interpersonal skills in completing shared tasks. Each lesson addressed specific motor skill tasks and motor problem solving tasks, adequate to the motor and technical skills of the students. At the end of each lesson, 15 minutes were dedicated to the debriefing, highlighting positive and critical issues and providing feedback (not solutions) on unsolved questions. The control group followed a traditional instructional plan in PE classes, conducted through individual drills and repetition of exercises as a means of perfecting skills and procedures and direct instruction methodologies (Metzler, 2011). Each lesson followed this structure: a brief explanation of the goals of the lesson; a warm-up of 5 - 10 minutes with global and specific exercises; the main part of the lesson, consisting of motor skill tasks or technique-centered tasks; a cooldown phase was also applied at the end of the class, commonly with a free game or a competitive sport game.

\subsection{Measures}

Physical Self-Description Questionnaire Short (PSDQ-S). The Italian short version of the PSDQ by Scarpa, Gobbi, Paggiaro, and Carraro (2010) was administered to assess the physical self-concept. The Italian short form (Scarpa et al., 2010), developed by the English validation study (Peart, Marsh, \& Richards, 
2006), was obtained with 47 of the 70 statements of the long form of PSDQ (Marsh, Richards, Johnson, Roche, \& Tremayne, 1994), validated for the Italian context by Meleddu et al. (2002). The short form, like the long one, measures nine specific sub-constructs of physical self-concept (Health, Appearance, Activity, Body Fat, Sport, Coordination, Flexibility, Strength, Endurance) and two global constructs (Physical self-concept and Self-esteem). Each item is a declarative statement (e.g. "I am good at most sports") in which subjects respond on a six-point Likert scale ranging from 1 ("false") to 6 ("true"). Cronbach's alpha of PSDQ reported by Meleddu et al. (2002) ranged from 0.73 to 0.89 , with good construct validity. The short form reduces the length of the original version maintaining its psychometric properties, with coefficient alphas that ranged from 0.77 to 0.91 . The internal reliability for this study ranged from 0.65 to 0.92 for the subscales, whereas, considering the whole instrument, alphas are 0.88 (control group) and 0.85 (intervention group).

Physical Subscale of the Multidimensional Self-Concept Scale (MSCS). The MSCS (Bracken, 1992, 1993) is composed of 150 items assessing six self-concept, context-related dimensions (such as family life, interpersonal relationships, environmental control, emotion, academic success, and physical experience) in subjects between the ages of 9 and 19. Each dimension is measured by a 25 -item scale, which can be administered separately. Children are asked to give their rating for each statement on a scale of 1 ("strongly disagree") to 4 ("strongly agree"). For this study, we used the subscale related to the physical contexts, including 10 reverse-scored items. The items are constructed as statements, such as the positively-keyed items "I am an attractive person" and "I feel good about the way I look", or the negatively-keyed one "I'm not physically in good shape" and "I want to change a few parts of my body" (Bracken, 1993). The Italian version of MSCS has strong internal consistency reliabilities for the total score (Cronbach's alpha is 0.98 ) and the subscales (from 0.87 to 0.98). In particular, the coefficient alpha in the subscale related to the physical context is 0.92 . The instrument is also highly reliable over time, with subscale coefficients ranging from 0.73 to 0.81 (in the Physical experience subscale stability coefficient is 0.81 ), and a total score coefficient of 0.90 obtained by a four-week period retest protocol (Bracken, 1993). The internal reliability coefficient for this study is 0.80 (Cronbach's alpha).

Perceived Self-Efficacy in Physical Activity Questionnaire (APEF). The questionnaire APEF (Caprara, 2001) was employed to measure the perceived barriers to maintenance of exercise behaviour. The APEF consists of 5 items, rated on a 4-point scale, from 1 = "very uncertain" to 4 = "very certain". In each item, subject expresses his/her degree of certainty or uncertainty in practicing physical activity when difficulties are encountered. The initial statement "I persist in my intention to do exercise, even if..." is followed by 5 items, such as "...I am worried”. The measure has good reliability and internal consistency (Cronbach's alpha is 0.88 ) (Caprara, 2001). The internal reliability for this study is 0.89 (Cronbach's alpha). 
Interpersonal Adjustment Questionnaire (QAI). The Interpersonal Adjustment Questionnaire for middle school students (Di Nuovo \& Magnano, 2013) consists of 23 items, in which subjects assess their level of agreement or disagreement on a 3-point scale ("Very", "Somewhat", and "Little or none" (true for me); "Often", "Sometimes", and "Rarely or never"). The version for middle school students includes four sub-scales that explore negative dimensions (or barriers) related to self-management in social situations: social context and family pressure, external locus of control, tendency to depression and psycho-somatization. The test has good levels of reliability in all of the subscales, with coefficient alphas of 0.82 for the tendency to depression subscale and 0.84 for the psycho-somatization problems subscale, in the external locus of control subscale $($ alpha $=0.83)$ and in the social context and family pressure subscale $($ alpha $=0.85)$.

\section{Results}

Means and standard deviations, in the intervention and control groups for all the variables at the pretest are shown in Table 1.

Table 1. Means and standard deviations for all the variables at the pretest.

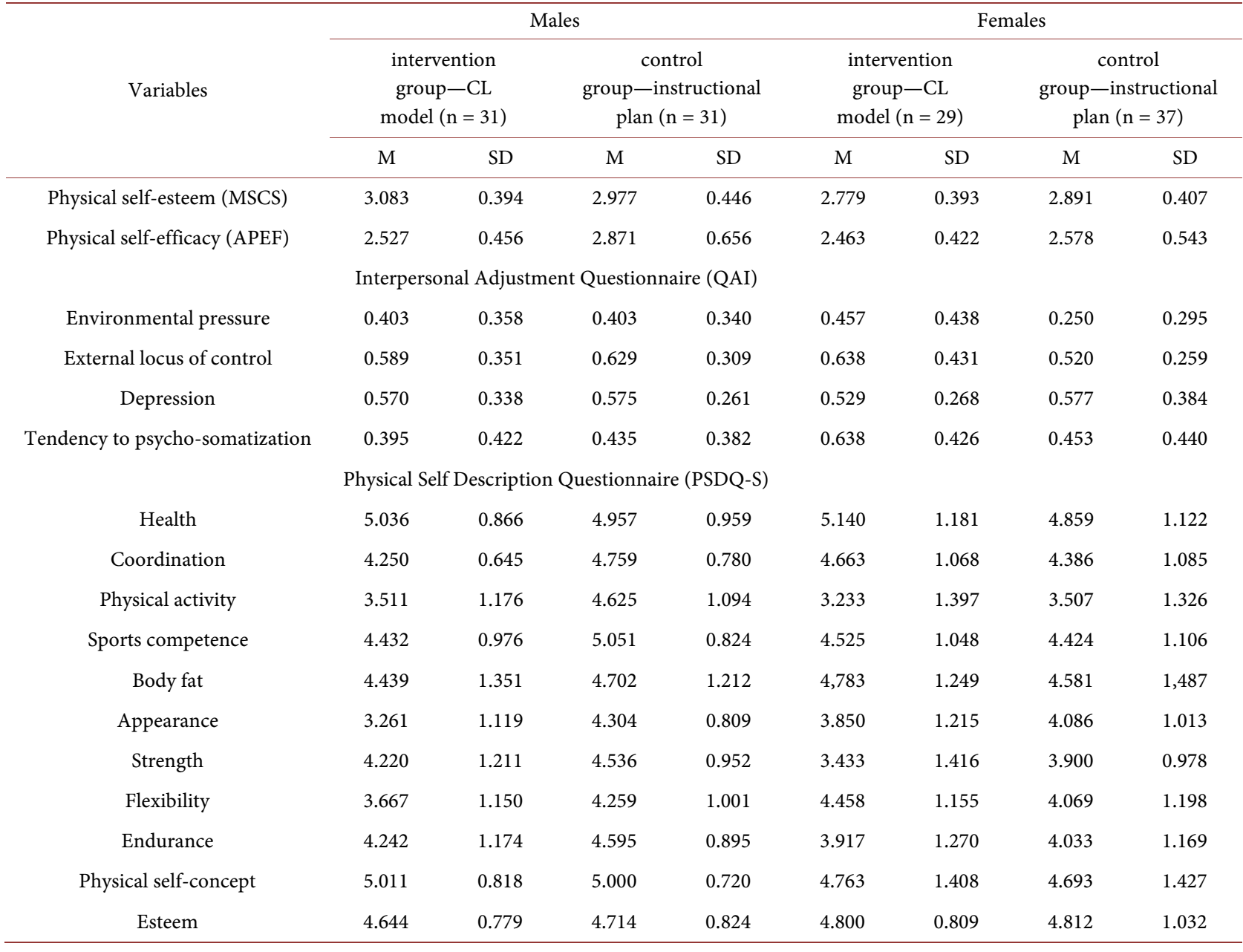


Student's t-test showed that, at pretest, there were no group differences in all variables. Repeated measure ANOVA was used to investigate whether the changes were related to time or to the interaction between time and intervention. In males, repeated measure ANOVAs detected a significant effect for Time in Physical self-efficacy (Pillai's Trace $=0.082 \mathrm{~F}=4.454 p=0.040 \mathrm{ES}=0.54$ ) with an increase in both groups due to the time. Repeated measure ANOVAs showed a decrease in the means in both groups in Environmental pressure (Pillai's Trace $=0.112 \mathrm{~F}=7.548 p=0.008 \mathrm{ES}=0.77)$ and in psycho-somatization tendency (Pillai's Trace $=0.083 \mathrm{~F}=5.442 p=0.023 \mathrm{ES}=0.63$ ). A significant effect due to the interaction between time and intervention was observed in only one subscale of PSDQ-S, the Perceived Sports Competence scale (Pillai's Trace = $0.105 \mathrm{~F}=5.493 p=0.023 \mathrm{ES}=0.63$ ), with an increase in the intervention group's means and a decrease in the control group's means. In females, results showed a decrease in the means of both groups in External Locus of control (Pillai's Trace $=0.092 \mathrm{~F}=6.501 p=0.013 \mathrm{ES}=0.71)$.

\section{Discussion and Conclusion}

This study examined the effects of two different teaching strategies on social skills, physical self-concept, and physical self-efficacy, in a sample of Italian Early Adolescents enrolled in middle school PE class. The initial hypothesis was that PE lessons based on the CL model will improve the participants' social skills and physical self-concept more than traditional methodology. Findings showed positive effects of the intervention in boys, only for perceived sports competence subscale of PSDQ-S. Related to the duration of the study, other positive effects observed in both groups were an increase in physical self-efficacy and a decrease in perceived environmental pressure and tendency to psycho-somatization. In girls no significant changes arising from the intervention were detected. A positive effect due to time was observed in external locus of control.

These results reflect the difficulty of producing changes in physical self-concept dimensions through educational interventions as highlighted by Lindwall and Lindgren (2005), but also the difficulty in delineating contents and method of physical education programs. As numerous studies have shown, physical self-concept tends to be stable and resistant to change, once its dimensions have become settled. Further experiences in sport and physical activity contexts, which are conflicting or not coherent with their body image, will not be easily accepted (Navarro-Paton et al., 2018). Therefore, a positive increase in physical self-concept in childhood and early adolescence, from teaching PE with a CL model, should be considered by educators and PE teachers in their educational practice. In order to prevent a decline in physical activity in adolescence an extension of the school PE with extracurricular activities is needed. Physical activities outside of school PE should be offered, offering adolescents the opportunity to discover their personal interests. Enabling choices among various sports and physical activities can broaden knowledge and information regarding physical activity practices. 
The intervention consisted of a CL model, in which boys found the opportunity to express their skills through physical performance. On the contrary to a previous study by Nicolosi et al. (2010), results indicated lower scores in perceived psychological barriers in peer relationships, but in an interdisciplinary PE program that integrated PE with math using a CL model. After the intervention, girls perceived themselves as less stressed by social and physical contexts and felt more confident with others. Furthermore, girls' posttest scores were higher than pretest in self-image. A combination of both teaching strategies (interdisciplinary PE and CL model) would seem more suited to bringing about a change in girls. As noted by Harvey and Jarrett (2014) in their review, research results of hybrid studies using multiple pedagogical approaches (e.g. CL model with Teaching Game for Understanding) were positive. This suggests that multiple pedagogical approaches could be used to enhance teaching and learning processes, but there have been few studies combining Interdisciplinary and Cooperative Learning in the Physical education context (Nicolosi, Sgrò, \& Lipoma, 2016).

Several limitations have been discussed. Firstly, this research involved students in their PE class. An additional extra-curricular intervention would be advisable to observe more effective results. This program should involve only volunteers and allow participants to choose among different activities. Secondly, a more effective involvement of PE teachers would improve the researcher's efforts in carrying out the educational activities. PE teachers could be engaged in preliminary training and also be engaged in the intervention. Further studies could investigate the mechanisms underlying the relationship between exercise and physical self, in different populations by age, physical activity levels, and educational context. To make significant and lasting effects on physical self-concept and socials skills, the PE curriculum could be modified using a mixed methodology of interdisciplinary PE and CL model. From an applied perspective, an interdisciplinary educational intervention could stimulate student motivation through cooperative and problem solving-based learning, using movement as an educational tool, and offering a new way to experience the PE settings. Moving away from a teacher-directed and a competitive model towards a student-centered pedagogy takes time, effort in adaptation, and critical reflection. Professional development programs must provide training in a variety of teaching models and practices (Ovens, Dyson, \& Smith, 2012). Educators and practitioners should be aware of the multidimensional nature of physical activities and their many educational possibilities when designing programs to enhance an integrated development of self. To support this change, university researchers should work with teachers on their professional development to promote multiple pedagogical approaches that fit the psychological and educational needs of their students in a "good enough" way, being a "good enough teacher" (Reid, 2019). Facing the complex settings of ongoing schooling implies constantly finding a balance in knowledge and teaching skills, the context in which they teach, and recognizing and meeting the needs of their students. In this 
sense, researchers and teachers should reflect on their practice with the goal of promoting lifelong physical activity and psychological wellbeing.

\section{Conflicts of Interest}

The authors declare no conflicts of interest regarding the publication of this paper.

\section{References}

Babic, M., Morgan, P., Plotnikoff, R., Lonsdale, C., White, R., \& Lubans, D. (2014). Physical Activity and Physical Self-Concept in Youth: Systematic Review and Meta-Analysis. Sports Medicine, 44, 1589-1601. https://doi.org/10.1007/s40279-014-0229-Z

Barrett, T. (2005). Effects of Cooperative Learning on the Performance of Sixth Grade Physical Education Students. Journal of Teaching in Physical Education, 24, 88-102. https://doi.org/10.1123/jtpe.24.1.88

Bracken, B. A. (1992). Multidimensional Self-Concept Scale Examiner's Manual. Austin, TX: Pro-Ed. https://doi.org/10.1037/t01247-000

Bracken, B. A. (1993). TMA. Test di valutazione multidimensionale dell'autostima. Trento: Erickson.

Caprara, G. V. (2001). La valutazione dell autoefficacia. Trento: Erickson.

Casey, A., Dyson, B., \& Campbell, A. (2009). Action Research in Physical Education: Focusing beyond Myself through Cooperative Learning. Educational Action Research, 17, 407-423. https://doi.org/10.1080/09650790903093508

Crocker, P. R. E., Sabiston, C., Forrester, S., Kowalski, N. C., Kowalski, K. C., \& McDonough, M. (2003). Predicting Change in Physical Activity, Dietary Restraint, and Physique Anxiety in Adolescent Girls: Examining Covariance in Physical Self-Perceptions. Canadian Journal of Public Health, 94, 332-337. https://doi.org/10.1007/BF03403555

Daley, A. (2002). Extra-Curricular Physical Activities and Physical Self-Perceptions in British 14-15 Year-Old Male and Female Adolescents. European Physical Education Review, 8, 37-49. https://doi.org/10.1177/1356336X020081003

Daley, A. J. (2007). Young People's Participation in Extracurricular Physical Education: A Study of 15-16 Year Olds in North-West England and North-East Wales. European Physical Education Review, 1, 339-368. https://doi.org/10.1177/1356336X07081997

Di Nuovo, S., \& Magnano, P. (2013). Competenze trasversali e scelte formative. Trento: Erickson.

Dyson, B. P., Linehan, N. R., \& Hastie, P. A. (2010). The Ecology of Cooperative Learning in Elementary Physical Education Classes. Journal of Teaching in Physical Education, 29, 113-130. https://doi.org/10.1123/jtpe.29.2.113

Dyson, B., \& Casey, A. (2012). Cooperative Learning in Physical Education. A Research-Based Approach. Oxon: Routledge. https://doi.org/10.4324/9780203132982

Dyson, B., \& Strachan, K. (2004). The Ecology of Cooperative Learning in a High School Physical Education Programme. Waikato Journal of Education, 10, 117-139. https://doi.org/10.15663/wje.v10i1.335

Ellerani, P. (2014). The Changing International Scenarios in Education and Training: Cooperative Environments and Capability Approach. Formazione \& Insegnamento, 11, 17-31.

Ellerani, P. (2017). Costruire l'ambiente di apprendimento. Prospettive di Cooperative Learning, Service Learning e Problem-Based Learning. Teramo: Lisciani. 
Esnaola Etxaniz, I. (2008). The Physical Self-Concept during the Life Span. Anales de Psicología, 24, 1-8.

Fox, K. R. (2000). Self-Esteem, Self-Perceptions and Exercise. International Journal of Sport Psychology, 31, 228-240.

Fox, K. R., \& Corbin, C. D. (1989). The Physical Self-Perception Profile: Development and Preliminary Validation. Journal of Sport and Exercise Psychology, 11, 408-430. https://doi.org/10.1123/jsep.11.4.408

Goudas, M., \& Magotsiou, E. (2009). The Effects of a Cooperative Physical Education Program on Students' Social Skills. Journal of Applied Sport Psychology, 21, 356-364. https://doi.org/10.1080/10413200903026058

Grineski, S. (1993). Achieving Educational Goals in Physical Education: A Missing Ingredient. Journal of Physical Education, Recreation and Dance, 64, 32-34. https://doi.org/10.1080/07303084.1993.10609972

Grineski, S. (1996). Cooperative Learning in Physical Education. Champaign, IL: Human Kinetics.

Harvey, S., \& Jarrett, K. (2014). A Review of the Game-Centred Approaches to Teaching and Coaching Literature since 2006. Physical Education and Sport Pedagogy, 19, 278-300. https://doi.org/10.1080/17408989.2012.754005

Johnson, D. W., Johnson, R. T., \& Holubec Johnson, E. (1994). The Nuts and Bolts of Cooperative Learning. Interaction Edina, MN: Book Company.

Khodaverdi, Z., Bahram, A., \& Robinson, L. E. (2015). Correlates of Physical Activity Behaviours in Young Iranian Girls. Child: Care, Health \& Development, 41, 903-910. https://doi.org/10.1111/cch.12253

Kirk, D. (2005). Physical Education, Youth Sport and Lifelong Participation: The Importance of Early Learning Experiences. European Physical Education Review, 11, 239-255. https://doi.org/10.1177/1356336X05056649

Lafont, L., Proeres, M., \& Vallet, C. (2007). Cooperative Group Learning in a Team Game: Role of Verbal Exchanges among Peers. Social Psychology of Education, 10, 93-113. https://doi.org/10.1007/s11218-006-9006-7

Lindwall, M., \& Lindgren, E.-C. (2005). The Effects of a 6-Month Exercise Intervention Programme on Physical Self-Perceptions and Social Physique Anxiety in Non-Physically Active Adolescent Swedish Girls. Psychology of Sport and Exercise, 6, 643-658. https://doi.org/10.1016/j.psychsport.2005.03.003

Marsh, H. W., \& Peart, N. (1988). Competitive and Cooperative Physical Fitness Training Programs for Girls: Effects on Physical Fitness and on Multidimensional Self-Concepts. Journal of Sport \& Exercise Psychology, 10, 390-407. https://doi.org/10.1123/jsep.10.4.390

Marsh, H. W., \& Shavelson, R. (1985). Self-Concept: Its Multifaceted, Hierarchical Structure. Educational Psychologist, 20, 107-123. https://doi.org/10.1207/s15326985ep2003_1

Marsh, H. W., Richards, G. E., Johnson, S., Roche, L., \& Tremayne, P. (1994). Physical Self-Description Questionnaire: Psychometric Properties and a Multitrait-Multimethod Analysis of Relations to Existing Instruments. Journal of Sport \& Exercise Psychology, 16, 270-305. https://doi.org/10.1123/jsep.16.3.270

Meleddu, M., Scalas, L. F., \& Guicciardi, M. (2002). Contributo alla validazione italiana del Physical Self-Description Questionnaire. Bollettino di Psicologia Applicata, 237, 36-52.

Metzler, M. W. (2011). Instructional Models for Physical Education. Scottsdale, AZ: Hol- 
comb Hathaway Publishers Inc.

Navarro-Paton, R., Rego Ferreira, B., \& García García, M. (2018). Impact of Cooperative Games on Physical Self-Concept in Elementary School Students. Retos, 34, 14-18. https://doi.org/10.47197/retos.v0i34.58803

Nicolosi, S., Schembri, R., Pignato, S., Lo Piccolo, A., Mango, P., Sgrò, F., \& Lipoma, M. (2010). Self and Physical Activities in Early Adolescence: An Action Research with Middle-School Students. Procedia Social and Behavioral Sciences, 9, 239-243. https://doi.org/10.1016/j.sbspro.2010.12.143

Nicolosi, S., Sgrò, F., \& Lipoma, M. (2016). Interdisciplinary Physical Education Teaching: A Literature Review. Formazione \& Insegnamento, 14, 35-45.

Ovens, A., Dyson, B., \& Smith, W. (2012). 1 Implementing the Cooperative Learning Model in Physical Education. In B. Dyson, \& A. Casey (Eds.), Cooperative Learning in Physical Education: A Research-Based Approach (pp.15-26). Oxon: Routledge. https://doi.org/10.4324/9780203132982

Peart, N., Marsh, H., \& Richards, G. (2006). The Physical Self Description Questionnaire: Furthering Research Linking Physical Self-Concept, Physical Activity and Physical Education. AARE Conference Paper Abstract, UWS Parramatta Campus.

Raiola, G. (2014). Teaching Method in Young Female Team of Volleyball. Journal of Physical Education and Sport, 14, 74-78.

Raiola, G., \& Tafuri, D. (2015). Teaching Method of Physical Education and Sports by Prescriptive or Heuristic Learning. Journal of Human Sport and Exercise, 10, S377-S384. https://doi.org/10.14198/jhse.2015.10.Proc1.28

Reid, J. (2019). What's Good Enough? Teacher Education and the Practice Challenge. Australian Educational Research, 46, 715-734. https://doi.org/10.1007/s13384-019-00348-w

Scarpa, S., Gobbi, E., Paggiaro, A., \& Carraro, A. (2010). Un contributo alla validazione italiana del Physical Self-Description Questionnaire Short. Giornale Italiano di Psicologia dello Sport, 8, 25-30.

Schneider, M., Dunton, G. F., \& Cooper, D. M. (2008). Physical Activity and Physical Self-Concept among Sedentary Adolescent Females. An Intervention Study. Psychology of Sport and Exercise, 9, 1-14. https://doi.org/10.1016/j.psychsport.2007.01.003

Thorburn, M., Jess, M., \& Atencio, M. (2011). Thinking Differently about Curriculum: Analysing the Potential Contribution of Physical Education as Part of "Health and Wellbeing" during a Time of Revised Curriculum Ambitions in Scotland. Physical Education and Sport Pedagogy, 16, 383-398. https://doi.org/10.1080/17408989.2011.557653

Tinning, R. (2012). Foreword. In B. Dyson, \& A. Casey (Eds.), Cooperative Learning in Physical Education. A Research-Based Approach (pp. XV-XVI). Oxon: Routledge. 